\title{
THE SOIL QUESTION IN CANADIAN FORESTRY*
}

\author{
C. Heimburger
}

$\mathrm{T}^{\mathrm{H}}$

HE aim of this paper should be to find out where in Canadian Forestry the question of soils comes up and where it is most probable to look for results of its application. There are two sides in forestry where a consideration of the soil is nowadays becoming more important and promises to be of some value. This is in forest type classification and in forest management.

In the past years there has been a growing interest in forest type classification, both in Canada and in the United States. Foresters have long realized the value of some kind of classification of the forest. In fact, the purpose of every forest survey or timber cruise nearly always has been first to find out how much and what kind of forest there was on the limits, and then to locate the ways of access and exploitation. Such names as Pine Flat, Mixedwood Slope, Hardwood Ridge or Spruce Muskeg have a very definite meaning with those who describe them and work in them. It usually does not only mean that there is pine on a pine flat, and spruce in muskeg, but also that the country where the pine is growing is flat and probably has a gravelly or sandy soil, and that the spruce is growing in a certain kind of peat bog. This again means entirely different methods of logging and transportation in order to get the wood. It also means that the land has been able to grow certain kinds of timber and that it probably will do it again.

With the growth of the industry larger and larger tracts have come under exploitation and it was soon found out that there were different kinds of Pine Flats, of Hardwood Ridges, of Spruce Muskegs, and so on. The task of subdividing large tracts of land into these units soon became too great and this idea is now largely abandoned. Forest Type now usually means cover type. The limits are subdivided into a number of stands, based on their composition of three species, their size, age and density. These stands are then grouped into a number of more or less well defined types. In recent years a topographic map or a map showing the main watersheds, together with a type map, are used as a basis for forest operations. It is then up to the contractor, the sub-contractor or the camp foreman to go further into details and to use his knowledge and his experience in the best way he can. The types are mostly of local importance. Efforts have been made several times to devise a set of standard types, to be used in whole forest regions into which the country is subdivided. From the standpoint of pure forest exploitation a system such as this works fairly well, especially if more up-to-date methods

* Paper presented at the Woodlands Section Pulp and Paper Association, Jan. 26, 1933. 
of forest surveying are introduced and more uniform methods of stand description are used.

But we must go further than that. Even in these times of over-production we must look for the future. There are, and most probably will be for many years to come, large areas where controlled exploitation is the most reasonable practice. There also are large areas where a certain amount of fire protection and some kind of rough cutting regulation will be sufficient. On the other hand there are large areas where the present degree of forest protection and other means of ensuring a future crop are very inadequate. Here much more intensive and efficient methods for obtaining a constant and even an increasing wood production are badly needed. A classification of forest lands into at least these 3 classes becomes more necessary as the economic side of forest management gains in importance. To learn and to decide what to do with the land is also important for the economic welfare of the country.

The fertility of the soil is one of the deciding factors in such a classification. Soil, together with climate, mainly decide the so-called forest producing capacity or site quality of forest lands. It so happens that we are mostly interested in the cutting and maintenance of softwood stands, chiefly of Spruce, Pine and Balsam. These softwoods usually grow best on medium fertile soils. Poor sites for softwoods have either poor soils resulting in slow growth and small sizes, or rich soils producing hardwood stands or at best mixedwood stands with a good growth but a poor yield of softwoods per acre. It is therefore reasonable to concentrate efforts for fire protection, more efficient cutting regulations and care for reproduction on regions or areas with medium fertile soils. Areas with mostly poor soils will not pay for investment. Areas with rich soils will require additional efforts to produce fully stocked softwood stands. It will often depend on local conditions whether large areas with medium fertile soils or smaller areas with rich soils are desirable. Under more extensive forestry conditions the first class of land probably in the long run will prove to be the best.

Efforts have already been made to classify forest land with regard to degree of protection. This is only one side of the question. The other side is a more definite knowledge of what kind of land is being protected. This will help to concentrate efforts on the most valuable and promising areas. Forest land is in itself very different in fire susceptibility. There are regions in Eastern Quebec where the climate is moist and the ground is covered with a thick layer of moss. Here a fire when it happens to occur, rarely destroys much of the ground cover, and often improves the reproductive capacity of the soil to softwoods. Further west in the drier region of Central and Western Ontario, we often see White Pine country with but a thin layer of needles and duff on the ground. Such a forest represents a much greater fire hazard. 
Much more profound and disastrous changes in the ground cover are usually caused by a fire and it takes a much longer time for the country to come back to softwoods. An investigation of any fairly large area where a fire was allowed to burn itself out, will disclose marked differences in its effects and causes of extinction. It will also show a varying degree of injury to the stand and the composition of the next crop, depending chiefly upon the soil. Such differences may often seem to be of minor importance, yet they may decide the fate and value of the land for many years to come. Also from this standpoint a classification of forest soil should be of some value.

A system embracing site quality, fire susceptibility and tendency to reproduce certain tree species seems therefore to be the most valuable from the standpoint of forest management. After the country has been subdivided into a number of forest regions, based chiefly on climate, a more detailed classification based on soils will be the next step. In Quebec, Ontario, Saskatchewan, Alberta and British Columbia some work has been done using the ground vegetation of the forest as indicators of site equality. The results obtained so far seem to be quite promising. After careful observations in nature some plants are chosen as indicators of certain soil qualities and conditions. A set of so-called indicator types is established for a forest region, corresponding fairly well with differences in growth and yield of the more important tree species, within the region. It seems only natural that at least some of these types would show marked differences also in the other characters mentioned. If well chosen, they should represent natural biological units, or average sets of natural conditions most frequently met with on fairly large areas.

Often very similar indicator types and with them stands of similar growth and appearance are found on very different soils. A spruce swamp can belong to the same site class expressed by its growth, as a spruce ledge. This means that different sets of natural conditions can produce similar results.

A site classification based only on growth will not take all this into account. While growth may be similar, other characters such as capacity for reproduction, fire susceptibility and ease of exploitation may be strikingly different. A description of the soil and topography will therefore be very useful as a supplement to a set of indicator types for a forest region.

It is often nearly impossible to classify more recently burned-over areas into indicator types. The ground cover is so changed by the fire and the opening up of the stand, and so varied, due to different degrees of burning, that it at first seems hopeless to undertake any kind of classification. It will be more promising to compare such burns with undisturbed areas having the same soil and topography than simply to classify them as burns and to describe the present vegetation. 
From all this it will be seen that all forest land is not the same for timber growing purposes. Some land just naturally seems to come back to softwoods, while other land reverts to hardwoods and only after a long time is ready for another cut. It is a natural advantage that large areas in Canada are too poor for growing tolerant hardwoods and yet not poor enough to exclude fairly rapidly growing softwoods. From the standpoint of pulp production there is a further advantage in that these lands are fairly easily accessible.

The history of pulpwood exploitation in Canada may briefly be summarized as follows: at first operations were conducted near the more densely settled parts of the country, at the foot of the main valleys in the Lake Ontario-St. Lawrence River drainage system. This is largely hardwood and mixedwood country; well growing hardwoods or fairly well growing tolerant hardwoods in mixture with very valuable softwoods. The soils are either composed of rich well drained glacial till or fertile alluvial deposits. These forests largely came back to hardwoods after the softwoods were taken out, or have been cleared for farming. When this source of softwoods gave out the industry started to move further up the valleys, opening up new country until it is now operating largely in pure softwood land. The best glacial till in this zone will in the worst case grow a mixed forest with intolerant hardwoods and the fertile alluvial deposits are carrying spruce flats instead of hardwood swamps as further down in the valley. Thus the movement has also been from rich to poorer and poorer soils. This is very well illustrated by the drainage systems of rivers flowing into the St. Lawrence River from the North. The pure softwood land is either coming back to intolerant hardwoods after cutting or fire, or to softwoods again.. If the development continues along the present lines the industry will move still further up the valleys into still poorer land until it reaches stands that will not be profitable to operate in. In the meanwhile second growth stands are coming up on softwood land or on abandoned farms, mostly on old hardwood land. It is interesting to note that poor farming often can exhaust the upper layers of the soil to a condition where it will not come back to tolerant hardwoods. Exhaustion of the upper soil layers and subsequent grazing favour the young ooftwoods in that competition with hardwoods is reduced. Below the plow furrows the soil often is rich and the trees are able to utilize it as soon as their roots reach down to it. The stands are often very open and the trees knotty and of no use for pulpwood. This is not caused by the soil but is the result of poor establishment or excessive grazing.

Sooner or later the pulpwood industry will, at least in part, have come back to second grown stands. It will then depend on transportation facilities and on soil quality what kind of second growth stands will be the most suitable to operate in and to establish with a far-sighted forestry in view. Abandoned 
farm lands have the advantage of being easily accessible and with proper reforestation will produce very rapidly growing softwoods. Old softwood land is less accessible, grows softwoods at a slower rate but is larger in area. Moreover, it is possible there, by very simple means, to let nature do most of the work. The costs and returns of intensive forestry on small areas or of extensive forestry on large areas will probably have to be weighed against each other for each particular set of conditions. In every case the question of soil, its quality and condition will be of deciding importance.

From the standpoint of pure exploitation there is hardly any need of going deeper into the soil question. As soon as a next crop is considered in any cutting operation, the maintenance of the wood producing capacity of the soil is just as important as fire protection or a cutting regulation.

Man usually influences the forest through cutting and fire. Cutting can influence the soil in several ways. Whether it is a clear cutting or a partial cutting, which may or may not be followed by a fire in spring or in late summer, the result is usually a disturbance of previous soil conditions. The disturbance will vary with the degree of the opening up of the stand, and with soil quality. Fires, especially severe slash fires in late summer, as well as windfalls, will tend to accelerate the effects of cutting. It may result in a temporary or prolonged set-back of previous yield capacity, or it may cause a better reproduction and more rapid growth of the succeeding stand. While very little is known as yet about the details of each particular set of conditions, the general trends can be recognized and can be used in a rough way in present methods of forest management.

The reaction of the soil and the vegetation towards such a disturbance is usually fairly closely correlated with site quality. The question of weed species is also closely linked with the success or failure of establishing a valuable stand after cutting or fire.

Our aim should be to utilize such soil disturbances, to benefit from the increased amounts of available plant food brought about by humus decomposition, and possibly to avoid or to shorten the succeeding wasteful period of weed-growth. The key to this situation seems to lie in logging and especially in the preparation of stands for logging.

Each site class will probably be found to have its own particular set of ways to react upon different kinds of soil disturbance. In general, it may be said that the richer the soil the more vigorous and rapid will be the reaction.

A poor site such as a sandy pine flat or a rocky ledge will react most slowly of all. Clear cutting will cause only a few weeds to come up for a short time and subsequent fires will tend to destroy the soil and to postpone reproduction. If left open for a long time, the land becomes very difficult to reproduce 
to softwoods, chiefly due to soil changes. The changes are so slow, however, that there is a long period of good seedbed conditions after the cutting.

A medium fertile site such as a spruce flat, or a mixedwood stand of the usual Spruce-Balsam-White Birch-Poplar combination, or a White Pine flat, will react in a different way. Dense growth of Raspberry, Fireweed, abundant Poplar sprouts or Fire Cherry and White Birch seedlings, is the usual thing after cutting or fire. Subsequent fires tend to eliminate established softwood seedlings, but they also eliminate or weaken some of the weed species. Only for a short period after cutting are there good reproduction and seedbed conditions. After a fairly long period of time, the weeds begin to open up and then again there is an increasing chance for softwood reproduction.

A rich site, such as a mixedwood slope of sof twoods and intolerant hardwoods, will again behave differently. Upon the slightest change, such as a moderate partial cut of softwoods, the hardwoods, and especially weedy hardwoods such as Mountain Maple, Hazel and Red Maple will rapidly come in in dense masses and prevent the establishment of new softwoods almost immediately. It will need a long time, often a century or more, before adequate seedbed conditions for softwoods again are at hand. A fire will tend to favor intolerent weed species and to shorten the subsequent weed stage.

Any opening up of the stand will tend to weaken or to kill old Hemlock, Yellow Birch and Balsam. Recent observations show that certain soil disturb. ances on rich and medium rich sites are unfavourable to the establishment of Spruce seedlings, even though weeds are scarce or absent. Balsam and White Spruce do not react in a similar way. This may be one of the causes of the increased proportion of Balsam in second growth stands. White spruce is too intolerant for this, and only on old pastures is there a chance for it to avoid the competition of weeds.

With these facts at hand there seem to be numerous possibilities for a cheap establishment of softwood crops.

European practice has long since established several cutting systems in order to utilize some of the conditions mentioned above. The main idea is to cut heavily and leave seed trees with due regard to windfall on poor and medium fertile soils. On rich soils a more gradual opening up of the stand is used, in order to avoid the weeds; or artificial regeneration is resorted to, followed by weedings and cleanings.

It is very doubtful whether any European method can be applied on fertile soils in Canada, i.e., applied with economic success and ability to produce wood that will be able to compete on the world market. A partial cut of softwoods will very soon reach an economic limit. Beyond this limit it will 
cease to be a profitable forestry operation and change into a sacrifice or an expensive experiment.

Yet there seems to be at least one way of solving this problem, and this is girdling of hardwoods to release conifers: so far it means girdling of tolerant hardwoods in mixedwood stands on fertile soils. It can also be changed into girdling of hardwoods to insure softwood reproduction, and probably with very good results. We have here a method that enables us to cause just the right kind of change in soil conditions, a change that is favorable for softwood reproduction and yet unfavorable for competing hardwood weeds. There is also a chance that this method may prove very useful on medium fertile soils when applied to intolerant hardwoods.

The fact that repeated fires tend to eliminate weed species and to shorten the period of their dominance, can also be utilized in establishment of cheap softwood stands, on medium fertile soils. Often the soil and ground vegetation indicate just the right stage for abundant reseeding, but seeds are lacking. It is possible that a combined girdling and reseeding or replanting will be one way to utilize old burns. There are far better prospects in the application of reforestation to middle aged and old second growth hardwood stands on old burns than on open land with invading weeds. Most of the soil treatment in agriculture is done because of the weeds. In forestry we must adapt our methods to the weeds and utilize their soil improving capacity.

It has been shown that second growth hardwood stands improve the humus condition through their litter. Moreover, they represent much less fire hazard than recently cut over mixedwood stands. A very gradual opening up of the stand brought about by girdling will tend to maintain and to improve the favorable soil condition caused by the hardwoods. The gradual dying off of the hardwoods will not as a rule create any appreciable fire hazard, as recent slash decay studies are showing.

Very young softwood seedlings are most tolerant of shade. Later, with increased size, their tolerance decreases. As stated above, certain soil changes are unfavorable for the establishment of Spruce seedlings. These facts ought to fit very well into the conditions brought about by girdling. During the first years after girdling, when the forest is still dark, softwoods ought to come in, either naturally or artificially. Later, the hardwoods begin to die, the forest opens up and an increased rate of humus decomposition begins. The softwood seedlings should already be present at this stage, in order fully to utilize the new set of conditions.

Probably methods other than girdling, i.e., a cheaper, less severe method of injuring intolerant hardwoods, to cause a slow and gradual death will be necessary on rich sites that have come back to them after repeated fires.

Marking and leaving seed trees is being practised by several paper com- 
panies in Canada. From the soil standpoint it would seem that trees of seed bearing age ought to be left on poor sites, in order to utilize favorable seed bed conditions immediately after cutting. On medium fertile and rich sites leaving of younger seed trees will be advisable, both from the standpoint of immediate utilization and from the standpoint of the unavoidable period of dense weed growth, rapidly following the cut.

A preparation of such stands for cutting will include girdling or any other cheap means of gradual removal of hardwoods, well in advance of the cut. This will give the standing softwoods several chances to reproduce. During the cutting operation and the further period of development it will be the task of cut inspection and fire protection to care for the young softwood stands, established by utilizing formerly very favorable soil conditions.

It will probably be found easier to reproduce Balsam than Spruce, also with girdling, because Balsam seems to utilize sudden soil disturbances better than Spruce. If Spruce is more desirable than Balsam, less severe forms of girdling further in advance of the cut will tend to coordinate light and soil conditions in favor of the Spruce.

There are large accessible areas in Canada, where repeated fires have created second growth hardwood stands that are just old enough to start a natural or artificial opening up and replacement by softwoods.

Also here a site classification taking soil and vegetation into account will be found very useful in utilizing their possibilities.

It is fortunate that fire protection in Canada is so well under way at the present time, that the establishment of young softwood stands and interest for soil conditions has every promise of not being a wasted effort.

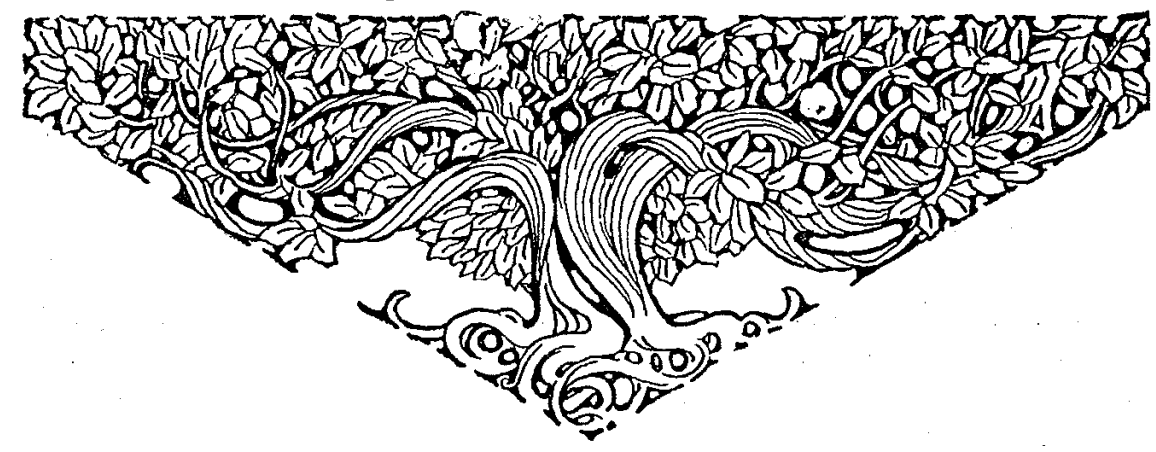

